\title{
Public Perceptions On Water Reuse Options: The Case Of Sulaibiya Wastewater Treatment Plant In Kuwait
}

Jasem M. Alhumoud, Kuwait University, Kuwait

David Madzikanda, Kuwait-Maastricht Business School, Kuwait

\begin{abstract}
The main sources of water in Kuwait are seawater desalination and groundwater. Reclaimed wastewater effluent could be an additional water source. Its use would reduce the volumes of recycled water being disposed of to the environment and it could reduce the demand for fresh water supplies. The results of a questionnaire survey of more than 1,500 random households residing in 64 districts in Metropolitan Kuwait are presented. The frequency distribution of the education level, knowledge of wastewater reuse, age, nationality and gender of the sample population are presented. In addition, we have presented the results of a survey of attitudes amongst residents of their willingness to use reclaimed water for a variety of purposes. The research analyzes the costs and benefits of using reclaimed water. The study concludes with useful recommendations for both the authorities and the citizens of Kuwait.
\end{abstract}

Keywords: perception, management, cost of water, wastewater treatment, Kuwait, Sulaibiya

\section{INTRODUCTION}

\subsection{General Overview}

$\mathrm{n}$ the face of population growth and increasing demand for water, rapid development of agriculture, increasing environmental degradation and impending climate change, arid countries such as Kuwait, need to critically assess their options for long-term security of water supply. The author believes that the
feasibility of reusing municipal wastewater should be part of that assessment; however, consumers need to be convinced of safety and negative perceptions toward drinking such water need to be overcome. The main sources of water in Kuwait and the other Gulf Cooperation Council (GCC) States are the desalination of seawater and groundwater. Over half of the world's desalination capacity is utilized in the GCC States which have an installed capacity in excess of 5,000 mega litres per day (MLd) (Al-Sofi, 1994; Al-Zubari, 1998; Alhumoud, 2008).

Indiscriminate discharges of untreated or partially treated wastewaters contribute to an increase in the pollution load entering waters of the Arabian Gulf. Problems also arise due to the location of water-intake points for desalination plants near wastewater discharges. Various strategies have been developed over the years in response to growing water demand. An integrated water management strategy currently implemented in Kuwait calls for developing unconventional water resources, such as desalination of seawater or brackish groundwater, water reuse, and water conservation measures.

Covering an area of $17,818 \mathrm{~km}^{2}$, Kuwait lies in the northwestern corner of the Arabian Gulf. It measures about $200 \mathrm{~km}$ from north to south and $170 \mathrm{~km}$ from east to west. The climate is typical of a desert (arid) region and receives only about $100 \mathrm{~mm}$ of rain annually. The percentage of water use in the domestic, industrial and agricultural sectors for Kuwait and the other GCC States is shown in Table 1. The table shows that Kuwait uses only 4 percent of its total water consumption for agriculture and 32 percent for industry, which is the complete opposite when compared with the rest of the GCC state, where they use almost 50 percent or more of their total water consumption in agriculture.

Reclaimed wastewater can be used for a variety of purposes as shown in Table 2 (Asano et al, 1996; Metcalf and Eddy, 2003). Type of wastewater treatment and the reliability degree required of the treatment processes and operations will depend on the reuse application. Agricultural irrigation and landscaping are the most common practices used worldwide for reclaimed wastewater. This use was first applied in northern Europe when sewage farms were developed (Vazquzio et al., 1996). In the USA, raw sewage use for irrigation was abandoned 
early in the twentieth century and by the 1930s, a minimum of primary treatment was required. However, the wastewater treatment processes of all the previous cases is, at most, tertiary treatment. Therefore, the resulted water cannot be used directly for drinking without going through further disinfections and other treatment processes.

Table 1: Water Use in Gulf Cooperation Council States

\begin{tabular}{|c|c|c|c|}
\hline \multirow[t]{2}{*}{ Country } & \multicolumn{3}{|c|}{$\%$ of total consumption for: } \\
\hline & Domestic & Industry & Agriculture \\
\hline Bahrain & 22 & 4 & 74 \\
\hline Kuwait & 64 & 32 & 4 \\
\hline Qatar & 45 & 8 & 47 \\
\hline Saudi Arabia & 45 & 8 & 47 \\
\hline United Arab Emirates & 11 & 9 & 80 \\
\hline
\end{tabular}

Table 2: Uses of Reclaimed Wastewater

\begin{tabular}{ll}
\hline Wastewater reuse & Examples \\
\hline Agricultural irrigation & Crop irrigation, commercial nurseries \\
Landscape irrigation & Parks, school yards, lawns, golf courses, cemeteries, greenbelts \\
Industrial & Cooling water, wash water, boiler feed, heavy construction \\
Tourism and recreation & Artificial lakes, fisheries, snowmaking \\
Groundwater recharge & Salt water intrusion control, groundwater replenishment \\
Oil field depressurization & Oil recovery \\
No-potable urban uses & Fire protection, refuse compaction, soil compaction, air conditioning, toilet flushing \\
Potable uses & Blending in water supply \\
\hline
\end{tabular}

(adapted from Mecalf and Eddy, 2003)

\subsection{Fresh Water Use}

Kuwait is situated in an extremely arid region that receives only about $100 \mathrm{~mm}$ (3.937 in) of rain annually. The average annual rainfall ranges from 40 to $240 \mathrm{~mm}$ and the total annual evaporation rate ranges from $2,500 \mathrm{~mm}$ in the coastal areas to more than $4,500 \mathrm{~mm}$ inland. The amount of renewable aquifer volume is very limited and shallow alluvial aquifers provide some renewable groundwater only in those limited coastal strips. Large deep aquifers are present in the region, which contain non-renewable supplies of fossil water, but have a finite life and quality limitations. However, even these are rapidly depleting. In the past, the people of Kuwait relied on a scant number of wells to satisfy their water needs. Those wells accompanied with fresh water transported by boats from Basra, Iraq, were the main source of water supply to the people. Transporting water by boats continued for some time. In 1939, a company was established to manage the fleet of water carriers from Iraq and three storage reservoirs were constructed on the shore. The first major breakthrough came in 1951 when Kuwait Oil Company (K.O.C) built a small 80,000 imperial gallons $\left(364 \mathrm{~m}^{3}\right)$ per day sea water desalination plant at the port of Al-Ahmadi (Mina AlAhmadi) and distributed part of the water to towns in Kuwait. The first major desalination plant was built in 1953 with a capacity of 1 million Imperial gallons per day $\left(4,546 \mathrm{~m}^{3} /\right.$ day). In 1978 , another desalination plant was built in Doha. The capacity of the Doha plant is 42 million Imperial gallons per day (190,936 $\left.\mathrm{m}^{3} / \mathrm{day}\right)$ (Al-Ruwaih et al., 2000; MEW 2007; MOP 2004).

Over the past three decades, the country has witnessed an unprecedented economic and social transformation. A significant portion of oil revenues has been used to modernize infrastructure and improve the living standards of the population. Water supply and sanitation services have been made accessible to a large percentage of the population. Life expectancy increased by about 10 years, to 74 years, during 1980-2000 and literacy rates increased from 20 percent to about 90 percent over the same period. Gross national income per capita (GNI) was estimated at about US\$ 19,480 in 2003 with gross domestic product (GDP) at about US\$ 16,240 and an average population growth rate of 3.5 percent (MOP, 2004; World Bank, 2005). 


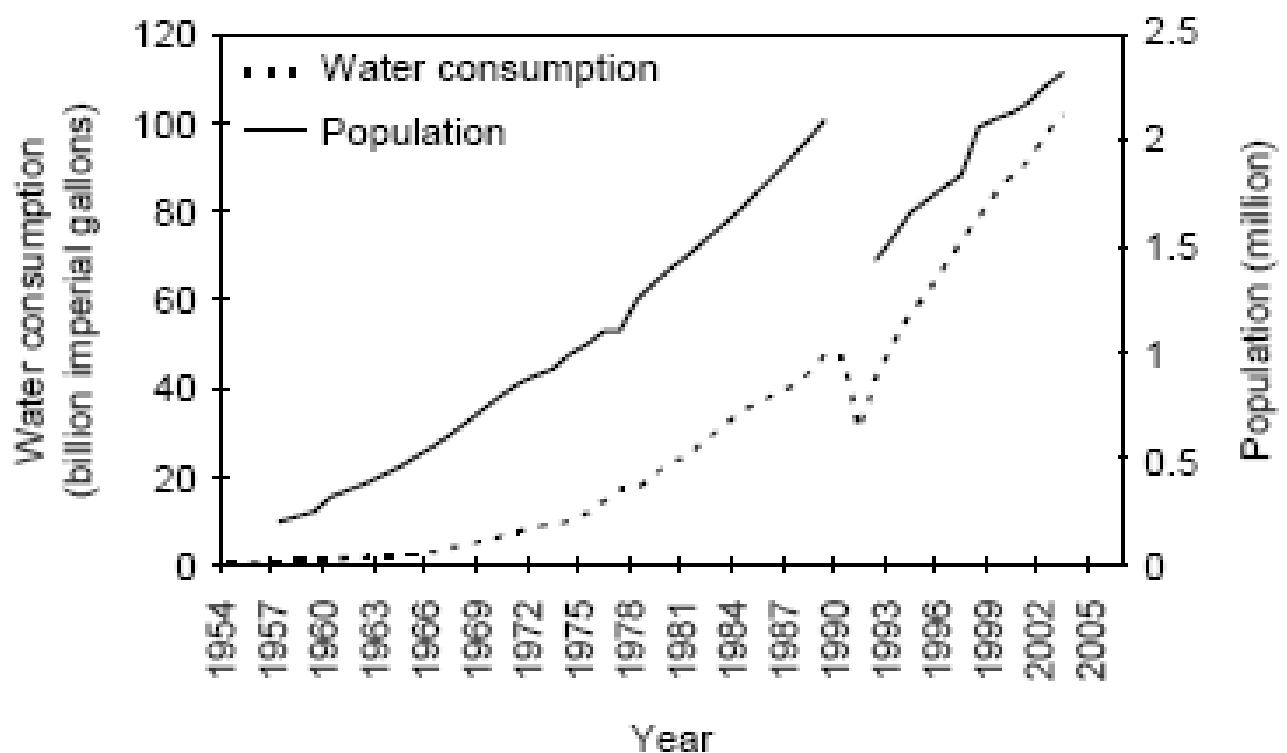

Figure 1: Trends in Fresh Water Consumption and Population Growth in Kuwait (1954-2005)

During this period, total water demand has increased dramatically as a result of high population growth, improvements in the standard of living, industrial development in major urban centers and efforts to increase food self-sufficiency. The total water use for all sectors increased by about four-and-a half times - from $186 \mathrm{million}^{3}$ to 993 million $\mathrm{m}^{3}$ - while the population nearly doubled from around 1.4 million to 2.54 million during 1980-2003.

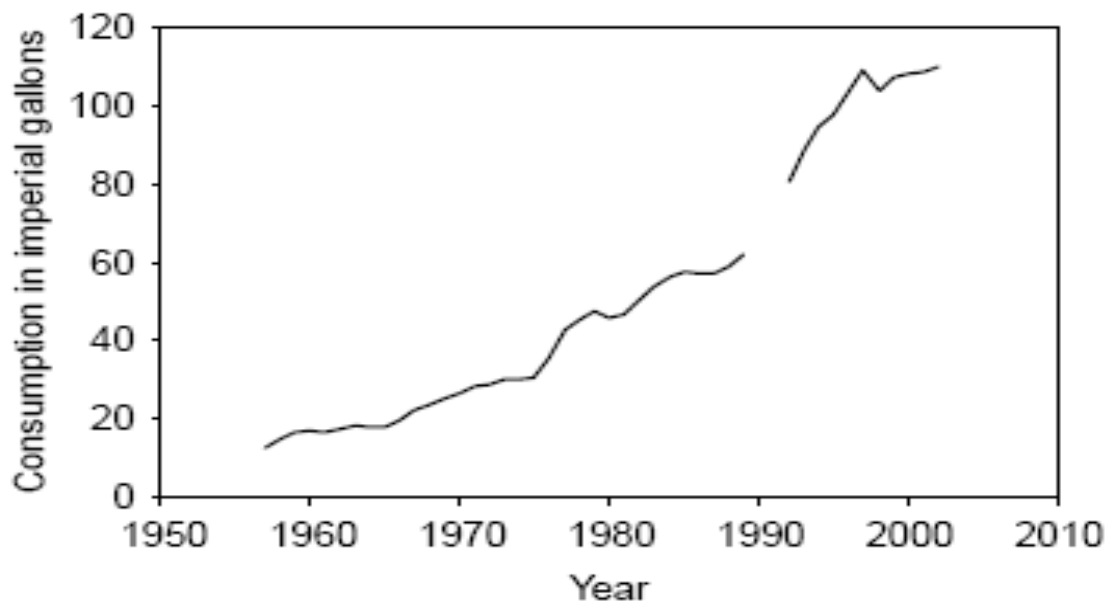

Figure 2: Daily per Capita Consumption of Fresh Water in Kuwait (1957-2003) 


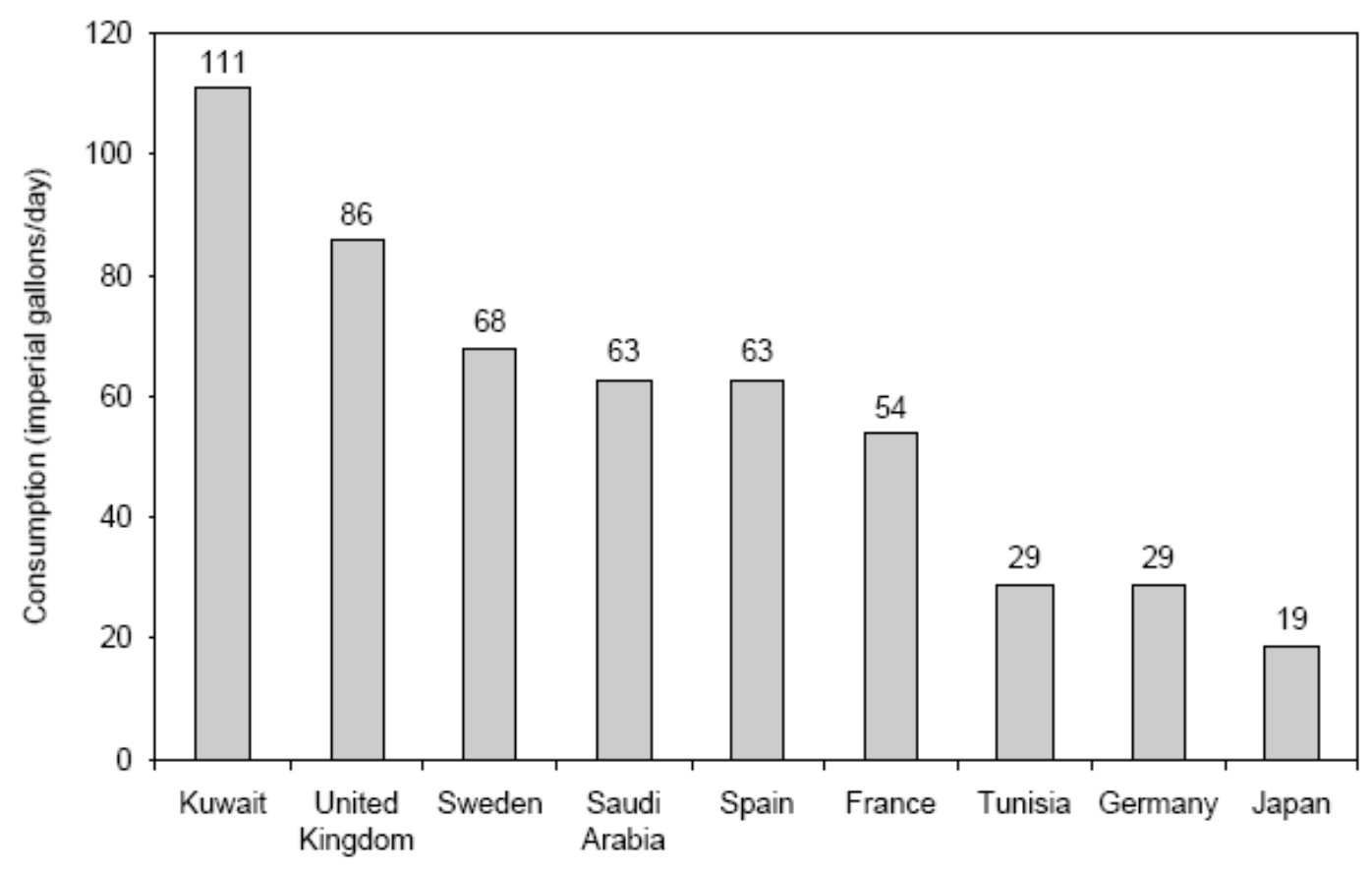

Figure 3: Daily per Capita Fresh Water Consumption in Different Countries

Water tariffs are generally quite low, representing, on the average, no more than 10 percent of cost, which implies that no incentives exist under current policies for consumers to save water. While 1,000 imperial gallons $\left(4,545 \mathrm{~m}^{3}\right)$ of water costs the Ministry of Electricirt and Water (MEW) KD 3.21 (US\$ 11.00) to produce, the customer is charged KD 0.8 (US\$ 2.72) for it. Furthermore, water metering and billing are only loosely applied to nationals. Some Kuwaitis have not been paying their water bills for over fifteen years and no action has been taken by the minisitry yet. Moreover, to make matters worse, recently the ministry has accridited KD 2,000.00 (US\$ $6,800.00)$ to every Kuwaiti household on their water bill. Current government policies of heavily subsiding the water sector could become counterproductive in the future. Heavy relience on subsidies will not only exacerbate rapidly rising water demand, but will also place an intolerable burden on national budgets. A substantial amount of water will have to be supplied by costly desalination plants. Even though newer and more cost efficient desalination technologies have become available, water subsidies alone could take away up to 10 percent of oil revenues by 2025 (World Bank, 2004; Busheri and Burney, 2003).

As it is noticed from Figure 1, the average consumption, and therefore production, of water has increased gradually with the exception of the years 1990 and 1991. In addition, Figures 2 and 3 show the per capita consumption in Kuwait and in various other countries, respectively.

The per capita water consumption was increasing yearly as well, with a slight drop during 1998. However, while there has been a small decrease in the per capita water consumption rate in Kuwait during last year, the current rate is still significantly higher than that reported for Western Europe, Japan and Middle Eastern Countries (KEPS, 2004; Alhajri, 2005). One should note that this decrease is due to the invasion of Iraq and the start of the Gulf war. Two factors explain the current alarming increase in urban water demand. The first is the rapid population growth and the second is the rise in per capita consumption. Average population growth in Kuwait over the last two decades is indeed among the highest in the world (around 3.5 percent per annum). More strikingly, the average daily water consumption per capita was only around 27 imperial gallons in the 1960s and has now increased to around 110 imperial gallons. Nowhere else in the world has per capita water consumption risen so rapidly over such a time period. Moreover, it is worth mentioning that by the end of 2003, the total length of the entire water network was $137,69 \mathrm{Km}$ while the number of consumers connected to the fresh water network totaled 122,111 and consumers connected to the brackish water network totaled 70,969 by the end of the same year (MOP, 2004). 


\section{TREATMENT PROCESSES}

\subsection{Traditional Treatment Plants in Kuwait}

Before 1956, wastewater was collected from septic tanks by tankers, which was then transported and discharged in areas chosen for 'green belt' within Kuwait city. Treatment of wastewater has begun after 1956, and treated effluent has been used in an experimental farm under the supervision of the agricultural department of the Ministry of Public Works (MPW) to irrigate alfalfa, a variety of trees and some flower plants.

Currently, wastewater is collected through an extensive sewer network with a total length of 7,000 km. Due to the country's flat terrain, frequent pumping of sewage is required. For this purpose, 16 main pumping stations and 43 secondary pumping stations are used. The collected wastewater is transported to three municipal plants for treatment and subsequent reuse or disposal. The three treatment plants are at Sulaiby, Riqqa, Jahra and Um AIHayman. Since the three wastewater treatment plants are owned and operated by MPW, continuous monitoring of the quality and characteristics of the wastewater streams at the plants are carried out by the MPW. The Environment Protection Authority (EPA) of Kuwait also carries out monthly monitoring of the effluents.

Ardiya is the largest and oldest treatment plant in Kuwait, dating back to the 1960s. It was constructed with a capacity of $100,000 \mathrm{~m}^{3 /}$ day, but due to the increase in water consumption and wastewater generation, an extension to the plant was added and the capacity increased to $150,000 \mathrm{~m}^{3} /$ day. The Riqqa treatment plant was constructed in 1981 with a capacity of $100,000 \mathrm{~m}^{3} /$ day. Recently, a study conducted by MPW suggested and recommended that the capacity of Riqqa treatment plant be increased to $180,000 \mathrm{~m}^{3} /$ day. The Jahra treatment plant was constructed in the late 1970 s and tertiary plants were added in 1982 . Presently, about $45,000 \mathrm{~m}^{3} / \mathrm{day}$ of domestic wastewater is treated at the Jahra plant and the design capacity of it is $70,000 \mathrm{~m}^{3} /$ day. The Jahra treatment plant is similar in design to the Riqqa plant. Um AI-Hayman is a new plant constructed in 2002 with a design capacity of 50,000 $\mathrm{m}^{3} /$ day. Figure 4 shows the treatment processes for the traditional wastewater treatment plants in Kuwait.

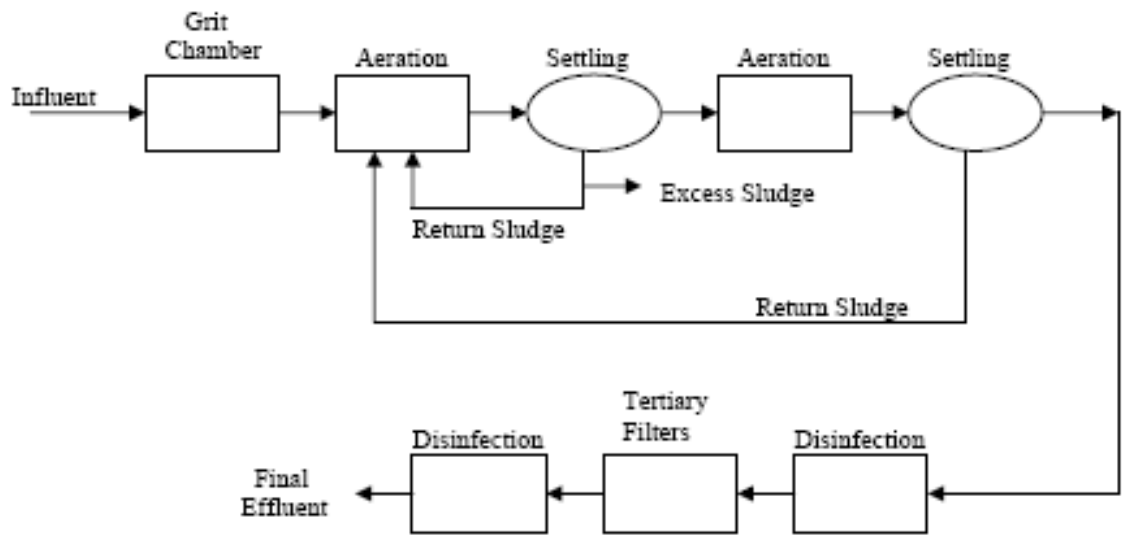

Figure 4: Major Treatment Steps for the Traditional Wastewater Treatment Processes in Kuwait

Lately, the amount of generated treated wastewater in Kuwait has increased considerably. This could be attributed to different reasons, such as: 1) population increase, 2) construction of new wastewater collection system, and (3) development of wastewater treated plants. Nevertheless, those amounts of treated wastewater make up only 40 percent of the total current water consumption due to lack of wastewater collection facilities in some areas, prohibition of industrial effluent discharges into the municipal wastewater collection system, and discharging parts of the untreated wastewater into the sea.

The tertiary treated wastewater is stored in a number of reservoirs, with an overall storage capacity of $400,000 \mathrm{~m}^{3}$, making water available for irrigation and improving the microbiological quality of the stored water. These reservoirs are located in the Sulaibiya area, from which water is pumped to the farms and landscape irrigation. In $1999,155,000 \mathrm{~m}^{3}$ of tertiary treated wastewater was used for irrigation, representing about 40 percent of the total treated effluent produced from the treatment plants. During winter seasons, this percentage is decreased to about 24 percent. Moreover, treated effluents that are not used for irrigation usually are disposed of to the sea. 


\subsection{The Advanced (Sulaibiya) Wastewater Treatment Plant}

Construction of the new and highly advanced wastewater treatment plant started in July 2002 and was completed in November 2004. Operation of the Sulaibiya plant started on December 2004. The Sulaibiya plant currently treats up to 375 million liter per day and it is designed for extension to 600 million liter per day. It is the first of its kind to be built in the Middle East and the largest in the world to use ultrafilteration (UF) and reverse osmosis (RO). The UF system will treat 100 percent of the flow after biological treatment; hence the feed to the RO system is also 375 million liter per day. The RO plant is designed for 85 percent water recovery. The plant influent is typical domestic sewage. The major treatment steps for the project are shown in Figure 5 (Gottberg et al, 2003; Gottberg and Vaccaro, 2003). The basic idea of the Sulaibiya Wastewater Treatment and Reclamation Project (WWT\&RP) is to replace the existing Ardiya WWTP with a new plant. The existing plant in Ardiya is no longer able to treat the increasing amount of wastewater. The tertiary-treated effluent from Ardiya plant contained a very high load of flocculated suspended solids, which required a much greater filter capacity than that used for sea water or ground water. The brackish water resources are no longer sufficient to cover the increasing non-potable water demand. Therefore, municipal effluent is given preliminary treatment at Ardiya and then piped $25 \mathrm{~km}$ (16 miles) to the Sulaibiya facility.

The Sulaibiya plant's final water quality is fully compliant with its design requirements and treats wastewater to World Health Organization (WHO) potable quality standards for non-potable use in agriculture, industry and aquifer recharge. The reclaimed water is chlorinated to protect it from re-infection. Figure 5 shows the treatment processes at Sulaibiya plant.

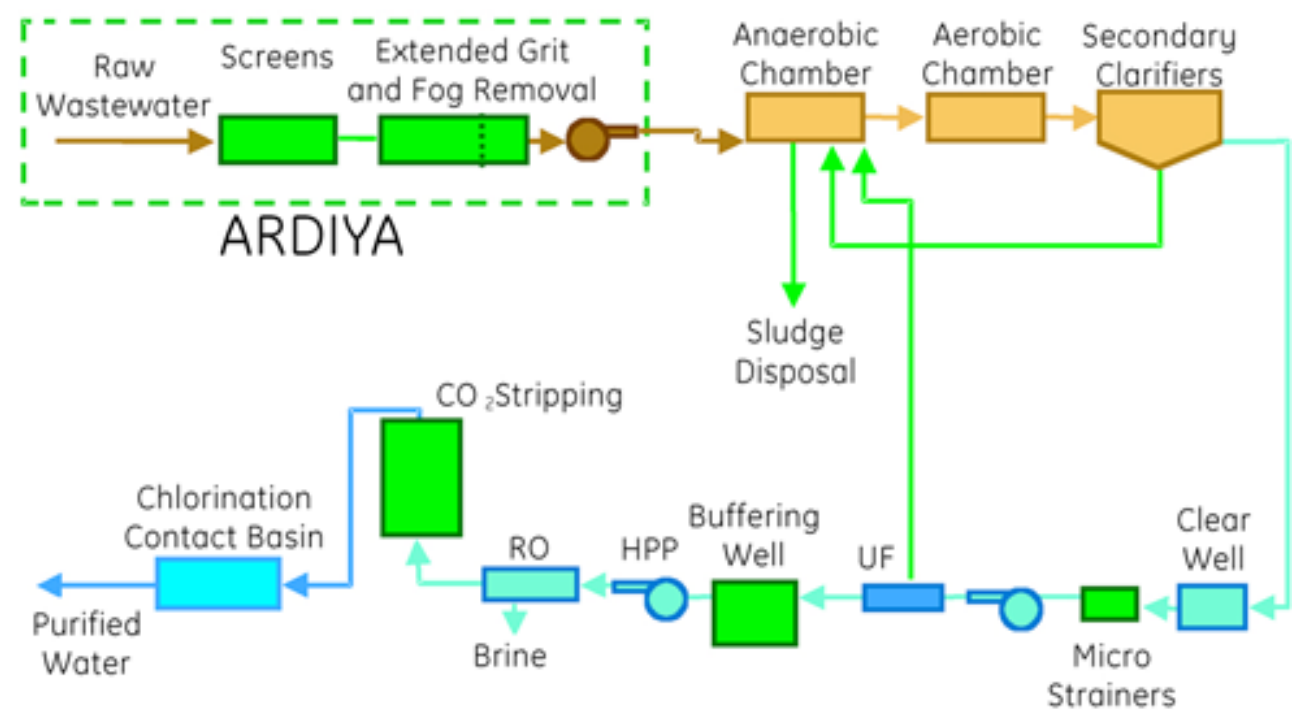

Figure 5: Major Treatment Steps at Suaibiya Plant

The water quality used as the basis of design and the projected treated water quality are detailed in Table 3 . The plant influent is typical domestic sewage. The WWTP is designed to produce an effluent with an average monthly value of less than $20 \mathrm{mg} / \mathrm{l} \mathrm{BOD}$ and $20 \mathrm{mg} / \mathrm{l} \mathrm{TSS}$. The water reclamation plant is designed to accommodate peaks in water quality due to upsets in performance of the WWTP. The average total dissolved solids (TDS) in the feed is $1,280 \mathrm{mg} / \mathrm{l}$, and the plant product is less than $100 \mathrm{mg} / \mathrm{l}$, significantly better than World Health Organization (WHO) potable water guidelines. 
Table 3: Water Quality Data

\begin{tabular}{|c|c|c|c|}
\hline Parameters & Effluent Plant* & Membrane Plant* & WHO Guidelines** \\
\hline $\mathrm{PH}$ & 7 & $6-9$ & $6.5-8.5$ \\
\hline $\mathrm{TSS}(\mathrm{mg} / \mathrm{l}) * * *$ & 12 & $<1$ & \\
\hline $\mathrm{BOD}(\mathrm{mg} / \mathrm{l})$ & 5 & $<1$ & \\
\hline Ammonia Nitrogen as $\mathrm{N}(\mathrm{mg} / \mathrm{l})$ & $<2$ & $<1$ & \\
\hline Nitrate (mg/l as $\mathrm{N})$ & $<9$ & $<1$ & 10 \\
\hline Phosphate (mg/l as PO4) & $<15$ & 2 & \\
\hline Fat, oil and grease $(\mathrm{mg} / \mathrm{l})$ & $<0.5$ & $<0.5$ & \\
\hline TDS (mg/l) & $<1280$ & 100 & 1000 \\
\hline
\end{tabular}

* Average monthly value; $* *$ for potable water; $* * * \pm 50 \%$

Menegaki et al. (2007) investigated the willingness to use and willingness to pay for recycled water in agriculture. Their results were based on surveys of farmers and consumers on the island of Crete, Greece. The basic conclusion emerging is that there is social acquiescence on the usage of recycled water. Farmers will agree to use recycled water for irrigation purposes and consumers will accept it as an ingredient of their food because they are willing to incorporate it in their food purchasing habits. The factors that most probably make farmers use recycled water are fresh water scarcity, involvement in environmental friendly actions, and their total water demand. Consumers, on the other hand, in their willingness to use recycled water are affected by their environmental awareness profile, income, price and age. When it comes to willingness to pay, for both farmers and consumers, none of the environmental awareness variables are significant. The cutoff points in consumers' willingness to use models show that information and education might be useful tools in making people realize the benefits of recycled water, allowing them to pass from "definitely negative" to "definitely positive" attitudes. Moreover, they concluded that consumers will require a price discount to encourage them to purchase crops grown with recycled water.

\section{REVIEW OF PRIOR RESEARCH INTO PUBLIC PERCEPTIONS}

Hurlimann (2009) carried out a survey on six water cartage businesses and interviews with local government and water authority officers in the state of Victoria, Australia. The review found that the cost of the carted water is up to 34 times higher than the cost of the delivery of the main water in Australian cities and towns. Formal review of the water cartage industry and associated regulations is recommended to assess the environmental, social and economic impacts of water cartage. Results demonstrate the importance of consulting with the community regarding water management options, indicating that economic feasibility of recycled water projects may be possible in areas experiencing prolonged water scarcity and restrictions to water use.

Dolnicar and Schafer (2009) conducted a comparative analysis of knowledge, perceptions, and acceptability, and determined segments of residents who are more open-minded than the general population toward the use of recycled and desalinated water. Their findings were based on a sample of 1,000 respondents to a designed questionnaire. They found out that Australian population discriminates between recycled and desalinated water. Although responses to the knowledge questions reveal gaps in the population's general level of knowledge, respondents understand that recycled water is the more environmentally friendly option, whereas desalinated water is perceived as less risky from a public health point of view. Results also indicate that Australians are mainly concerned about health issues that may be related to using water from alternative sources in their households while at the same time having only a low level of factual knowledge about the true health risks associated with desalinated and recycled water.

Dolnicar and Saunders (2006) focused on direct potable use only, identifying the main hindrances to be public health concerns. The main concerns raised by respondents surveyed by Higgins et al. (2002) in an Australian context were "public health and the environmental effect of microbiological agents". Marks (2006) identified quality and cost as the two main concerns among users at an Australian site.

A number of studies have investigated the association of socio-demographic descriptors and the acceptance of recycled water. The single factor that has been most frequently found to be associated with the acceptance levels of recycled water is the education of the individuals expressing their opinion, followed by age and knowledge about reuse, income and gender having been identified as associated in one third of the studies. Dolnicar and Saunders (2006) based their recommendation on the repeated finding that socio-demographic characteristics of the population are associated with acceptance rates for recycled water and consequently proposed the introduction in high-status 
communities first. In addition, they suggested a behavioral modification approach and recommended simple strategies as prize draws for volunteers to drink recycled water in order to decrease the level of prejudice against recycled water. Po et al. (2004) recommended community involvement, community empowerment and accurate and complete information policies as central success strategies for assuring public acceptance.

Hurlimann and McKay $(2007,2006)$ and Hurlimann (2009) examined the attitudes of an urban Australian community living at Mawson Lakes in South Australia, to using recycled water for non-potable domestic purposes. Their results indicated that ideally, to be most acceptable to the community, recycled water should be low in salt, colorless and odorless, while low in price. In addition, their results indicated the importance of certain attributes and the trade-offs made between attributes will vary depending on the use of recycled water. Moreover, their results indicated that respondents from higher income households may use more water. For example, they have larger houses on larger blocks of land, thus having more toilets, showers, and water using appliances, and having larger gardens that use a greater amount of water.

Kotchen et al. (2009) contacted 1,657 household residents in southern California, USA, and 1,005 interviews were completed, yielding a cooperation rate of 61 percent. The presence of pharmaceutical compounds in treated wastewater were investigated in those interviews. All survey respondents were at least 18 years of age and were the individuals that answered the call. In total, they found that 43 percent of the respondents are aware that medical compounds have been found in treated wastewater. Less than one-half of the respondents are aware that medical compounds have been found in treated wastewater and in surface waters, and that awareness affects disposal practices. While disposal of unused medications through the trash and toilet/sink are the most common practices, respondents that are aware of the issue are less likely to use these disposal routes and are more likely to return pharmaceuticals to the pharmacy or drop them off at hazardous waste centers. They concluded that one implication of efforts to increase awareness will be to affect disposal practices in environmentally beneficial ways.

\section{DATA AND METHODOLOGY}

Following a comprehensive review of the related literature and the establishment of organizational structure for the implementation of the research, a survey plan was designed. The computation of the sample size, the development of a questionnaire, the determination of sampling technique, and sample population were all addressed in the survey design. The computation of the sample size was made in accordance with the commonly utilized statistical equation (Walpole and Myers, 1985). A confidence level of 95 percent and an error level of \pm 5 percent were considered to be appropriate by the research team. By utilizing a recommended value of 0.5 for the standard deviation (for maximum possible standard error of the mean), the minimum required sample size may be computed with the following equation:

$$
\sqrt{N}=\left[\left(\mathrm{Z}_{1-\alpha / 2} * \mathrm{~S}\right) / e\right]
$$

where

$\mathrm{N} \quad=\quad$ the minimum required sample size.

$\mathrm{Z}=$ the number of units of the standard deviation in a standard normal distribution curve $(\mathrm{Z}=1.96 \%$,

$$
\alpha=5 \% \text { ). }
$$

$\alpha=$ significance level.

$\mathrm{S} \quad=$ standard deviation ( 0.5 when the true population standard deviation Is not known).

e $\quad=$ acceptable error $( \pm 5 \%)$.

Equation 1 and the above input values result in a minimum sample size of 385 .

A simple, but yet structured, questionnaire was designed (both in English and Arabic) and pre-tested to obtain information on education level, knowledge of wastewater reuse, age, nationality, and gender of the sample population, as well as the attitudes among residents of their willingness to use reclaimed water for a variety of purposes. The questionnaire, after being pre-tested and modified, was distributed to a systematic random sample of 2,000 households residing in the six governorates of metropolitan Kuwait. Special care was taken to ensure the representativeness of various socio-economic groups in the sample. The random sample of 2,000 households was interviewed in person. A total of 1,540 completed questionnaires (77 percent) were processed for the analysis. SAS software (SAS/ETS Statistics, 1991) was utilized for processing and analyzing the data. The interviews were conducted by senior year undergraduate and graduate students from Kuwait University. The objective of the study was to examine the attitude and willingness of using treated wastewater for different purposes, but mainly for domestic consumption purposes among people residing in Kuwait. 
The questionnaire contained the following questions, which shows the public's perception and acceptance of recycled water:

- A perceptions/knowledge question given to the respondents asked them to state whether or not each of a list of statements was true for recycling. The hypothesis underlying these items was that the general knowledge level about alternative water sources among the Kuwaiti population was low and, as a consequence, people held erroneous beliefs about recycling.

- $\quad$ A stated likelihood-of-use question given to the respondents asked them to state how likely they are to use recycled water for a list of purposes. This question format was adopted because it has been used successfully in most prior studies in which stated acceptance levels were measured empirically (Bruvold, 1988; Bruvold and Ward, 1970; Bruvold, 1972; Kasperson et al., 1974; Sims and Baumann, 1974; Stone and Kahle,1974; Olson et al.,1979; Bruvold et al.,1981; Milliken and Lohman, 1985; Po et al., 2004). In order to avoid bias arising from respondents who assumed different treatment procedures, respondents were given the following instructions for answering the question: "For the following questions, we will use the term 'recycled water' to describe 'purified wastewater or sewage' and we will assume that recycled water is treated to the same level of potable water quality. A variety of questions asked respondents to state their primary concerns with using recycled water. This was included to determine reasons for resistance to using recycled water.

In addition, several socio-demographic and behavioral variables were included in the survey - age, gender, education, occupation, and nationality. However, the major objective of the study was to figure out the acceptance level of the highly purified wastewater for personal use among the people of Kuwait.

While the study contains new elements that have not previously been investigated (knowledge/perceptions about water types, ranking of uses, and so on), some of the limitations of traditional public acceptance studies also apply to our study (Baumann, 1983; Comrie et al., 2003). For example, the questions about the likelihood of adoption are hypothetical, given that most of the respondents have had no prior experience with recycled water. Also, appearance and smell could not be included in the written online fieldwork as evaluation criteria for their likelihood of use. Neither does this study assume that the perceptions identified are stable or can be generalized beyond Kuwait (Russell, 2004).

Very few people in Kuwait have had personal experiences with alternative water sources, yet a recycled water scheme has received wide public attention in Kuwait for many years because of rain scarcity and very limited water resources. Although we assumed that respondents had formed opinions about alternative water sources, very few would have done so on the basis of personal experience. Their perceptions of alternative water sources were essentially a "brand image" problem at the time of this study. The perceptions/knowledge items in the survey represent items typical of brand image studies. Items were derived from prior studies and interviews with people residing in Kuwait. They were pre-tested to ensure understanding and non-redundancy and presented to respondents for evaluation.

At this point, it should also be noted that most people residing in Kuwait do not have a direct choice to use or not use recycled water. Dual reticulation systems would have to be installed for consumers to have the actual choice at the household level, which is not possible for individual households, but only at the level of residential developments. Consequently, increasing the acceptance levels for alternative water sources at this state of development of alternative water sources in Kuwait is not expected to lead to instant behavioral changes. Instead, high public acceptance levels are essential to make the construction of new recycling plants which will have politically viable consequences for household water supplies.

\section{FINDINGS AND ANALYSIS}

The questionnaire/survey response rate was 78.6 percent $(n=2200)$, which is very satisfactory. Respondent fatigue was not evident in any data collected in the survey and no respondent was reported to have difficulty in completing it. To find the preference of the Kuwaiti people toward which type of fresh water they preferred to use; they were asked what type of source they use. Amazingly, 873 (57 percent) of the respondents said they use both tap and bottled for drinking, 524 (34 percent) said they use only bottled water for drinking, and only 154 (10 percent) use tap water only for drinking.

All of the sample households' socio-economic factors are presented in Table 4. The majority of the respondents (70.16 percent or 1,213) were Kuwaitis compared to 29.84 percent (516) non-Kuwaitis. The number of females (53.67 percent) was slightly more than males (46.33 percent). The education groups of the respondents were divided as follows: 16 percent with high school degree or less, 8.67 percent with an institute degree, 69.67 percent 
had some sort of college degree, and 5.67 percent had a graduate degree (M.S. or Ph.D.). The distribution of age of the respondents was as follows: 17 percent between 15 and 20 years old, 33 percent between 21 and 25 years old, 28 percent between 26 and 35 years old, 14 percent between 36 and 45 years old, and 8 percent more than 45 years old. In addition, Table 4.1 gives the level of wastewater use/reuse knowledge of the respondents. The analysis suggests that a high percentage of the people in Kuwait (38.33 percent) did not have a basic understanding of wastewater use while 47.33 percent had some idea and the rest (14.33 percent) had sufficient knowledge.

Table 4: Characteristics of Respondents

\begin{tabular}{cccc}
\hline Variable Name & Frequency & Percent & Cumulative Percent \\
\hline Knowledge of wastewater use: & & & \\
No idea at all & 663 & 38.33 & 38.33 \\
Some idea & 818 & 47.33 & 85.66 \\
Sufficient knowledge & 248 & 14.33 & 100.0 \\
Education: & & & 16.00 \\
High School or less & 277 & 16.00 & 24.67 \\
Institute & 150 & 8.67 & 94.34 \\
College & 1204 & 69.67 & 100.0 \\
Graduate Degree & 98 & 5.67 & 17.00 \\
15-20 & & & 50.00 \\
21-25 & 294 & 17.00 & 78.00 \\
36-35 & 571 & 33.00 & 92.00 \\
$\geq 45$ & 484 & 28.00 & 100.0 \\
Age (year): & 242 & 14.00 & \\
Kuwaiti & 138 & 8.00 & 70.16 \\
Non-Kuwaiti & & & 100.0
\end{tabular}

Table 5 shows that the overwhelming majority of the respondents (77.91 percent) objected to using reclaimed water for drinking and only 16.83 percent said they might consider drinking it. The majority of respondents (75.28 percent, 66.80 percent and 55.60 percent) did not object to using the reclaimed water for agricultural irrigation, car washing and house washing. In addition, Figure 6 shows that most of the respondents, even the ones that possessed enough knowledge about the subject, strongly opposed using reclaimed wastewater for human use (showering/bathing - 60.03 percent, clothes washing - 52.40 percent and cooking - 78 percent), regardless of its quality and cost.

Reasons and objections for not using treated wastewater were analyzed. Figure 7 gives the reasons for rejecting the use of treated wastewater:

- 69 percent reject its reuse for health reasons

- $\quad 54$ percent reject its use for psychological reasons

- $\quad$ about 29 percent reject it for religion beliefs

- 25 percent reject it because they do not trust the workmanship at the plant

- $\quad$ about 19 percent reject it due to the fear of mechanical breakdown

- 7 percent reject it for other reasons one reason.

The figures exceed 100 percent because some people were opposed to using reclaimed water for more than 
Table 5: People's Attitudes toward Effluent Reuse

\begin{tabular}{|c|c|c|c|}
\hline Type of use & Response & Frequency & Percent \\
\hline \multirow{3}{*}{ Agriculture /landscaping } & Yes & 1300 & 75.28 \\
\hline & No & 153 & 8.85 \\
\hline & May be & 276 & 15.96 \\
\hline \multirow[t]{3}{*}{ Car Washing } & Yes & 1155 & 66.80 \\
\hline & No & 288 & 16.66 \\
\hline & May be & 286 & 16.54 \\
\hline \multirow[t]{3}{*}{ House washing (floor scrubbing) } & Yes & 952 & 55.60 \\
\hline & No & 421 & 24.35 \\
\hline & May be & 356 & 20.59 \\
\hline \multirow[t]{3}{*}{ Clothes washing } & Yes & 362 & 20.94 \\
\hline & No & 906 & 52.40 \\
\hline & May be & 461 & 26.66 \\
\hline \multirow[t]{3}{*}{ Showering/bathing } & Yes & 262 & 15.15 \\
\hline & No & 1038 & 60.03 \\
\hline & May be & 429 & 24.81 \\
\hline \multirow[t]{3}{*}{ Cooking } & Yes & 144 & 8.33 \\
\hline & No & 1349 & 78.00 \\
\hline & May be & 236 & 13.67 \\
\hline \multirow[t]{3}{*}{ Drinking } & Yes & 91 & 5.26 \\
\hline & No & 1347 & 77.91 \\
\hline & May be & 291 & 16.83 \\
\hline
\end{tabular}

Respondents were asked about their knowledge concerning the reuse/standards of treated wastewater. About 38 percent (663) of the respondents had no knowledge at all about the treatment processes, while 47 percent (818) had some degree of knowledge, and only 14 percent (248) had enough knowledge about the wastewater reuse.

The study also showed that the average household water bill was US\$ 166.5 per month, the monthly household income was US\$ 5,500, the average family size was six, a typical family owned 3.5 vehicles and employed three servants, each person would shower or bath at least five times per week, and each household washed clothes at least four times per week and washed the entire house (floor scrubbing) twice a week. Also, 56.67 percent of the total respondents used bottled water alone for drinking, while 33.33 percent used tap water alone and 10 percent used both for drinking.

Respondents were also asked about the appearance and quality of tap water. Sixty eight percent of the households were concerned by color, 21 percent were concerned with taste, and 26 percent were concerned with the presence of impurities. Again, the total exceeds 100 percent because some people listed more than one concern.

People with high educational attainment showed a greater willingness, compared with other groups, to use treated wastewater for different purposes. This may be because they are more familiar with the different potential uses. Nearly 58 percent of the sample thought that fresh water supply "would" be a problem in the future. About 32 percent believed "to some extent" that it would be a problem and 10 percent said it would "not" be a problem. 


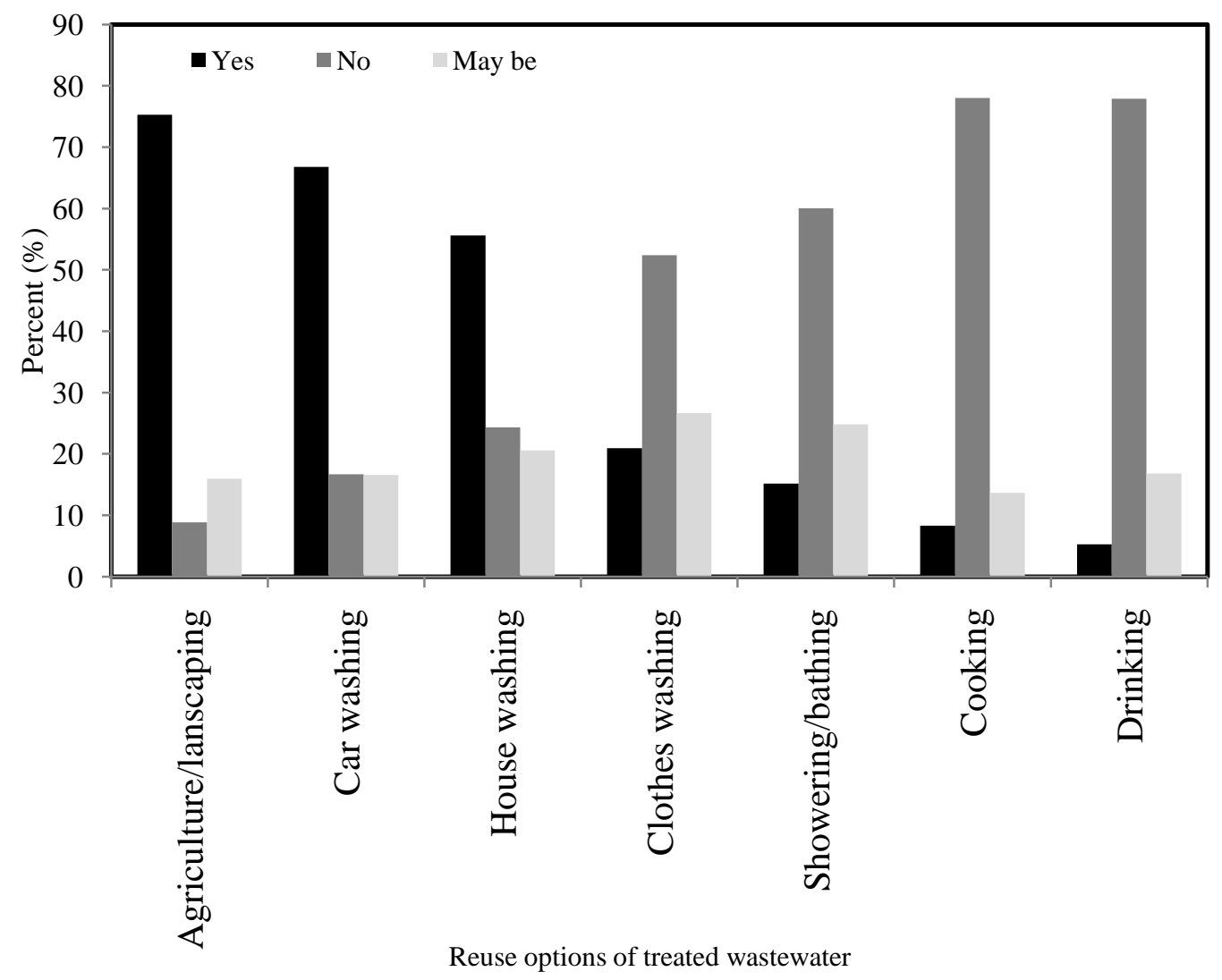

Figure 6: People's Attitudes toward Treated Wastewater Reuse

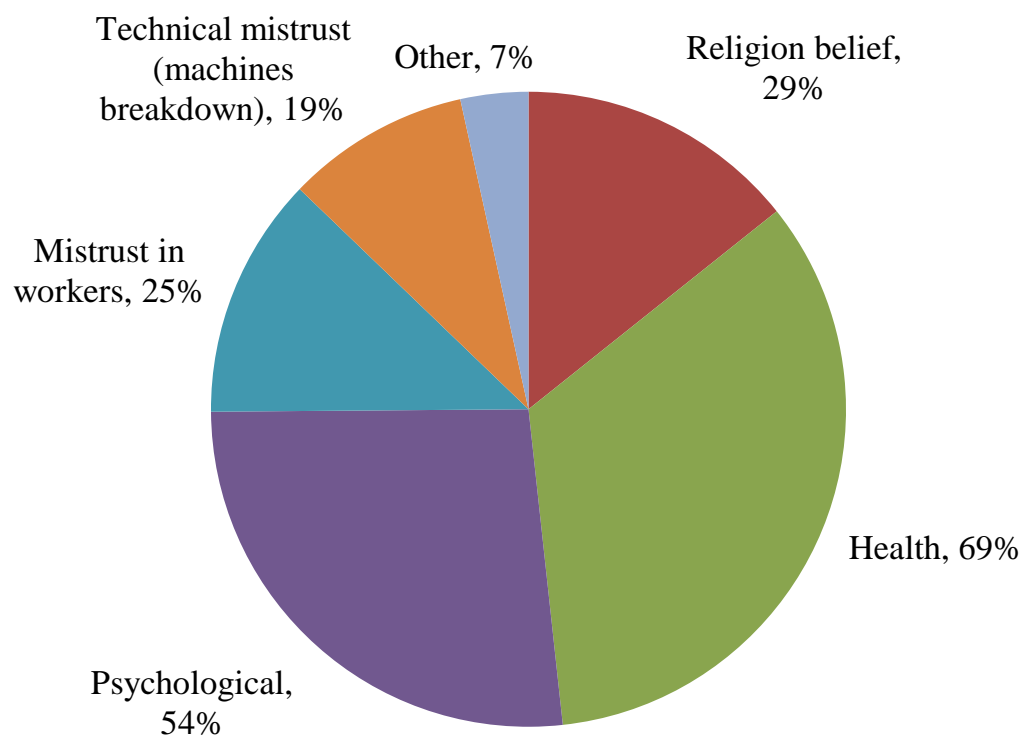

Figure 7: Reasons for Not Using Treated Wastewater 
Correlation analysis is usually employed to examine the degree of association between two variables. The result of the data analysis of correlations indicated that a number of characteristics and their wastewater reuse were positively and significantly (at the 95 percent significance level) correlated. Factors such as gender, age, education and knowledge of wastewater use all affect the wastewater reuse. Therefore, a correlation analysis was performed on the data to quantify the magnitude of these associations. For example, the willingness of reusing wastewater was positively correlated with the education $\left(\gamma_{\mathrm{xy}}=0.285, \mathrm{p}<0.0001\right)$, with the knowledge of wastewater use $\left(\gamma_{\mathrm{xy}}=\right.$ $0.251, \mathrm{p}<0.0001)$, with the age $\left(\gamma_{\mathrm{xy}}=0.218, \mathrm{p}<0.0001\right)$, with the gender $\left(\gamma_{\mathrm{xy}}=0.197, \mathrm{p}<0.0001\right)$, and with the nationality $\left(\gamma_{\mathrm{xy}}=0.192, \mathrm{p}<0.0001\right)$. In general, a major factor contributing to the reuse of treated wastewater is education. The higher the education level, the higher the acceptance level of reusing treated wastewater. However, in addition to the education level, a number of other variables may also significantly affect the reuse of wastewater. The knowledge of wastewater use is one such variable that contributes to higher levels of acceptance to wastewater reuse. Table 6 shows the correlation coefficient matrix.

Table 6: Matrix of Correlation Coefficient

\begin{tabular}{|c|c|c|c|c|c|c|c|c|}
\hline Var. & KTW & AGR & AUT & CLO & HOU & SHB & COK & DRK \\
\hline KTW & 1.00 & 0.503 & 0.409 & 0.117 & 0.176 & 0.097 & 0.072 & 0.037 \\
\hline AGR & & 1.00 & 0.323 & 0.239 & 0.166 & 0.144 & 0.094 & 0.074 \\
\hline AUT & & & 1.00 & 0.232 & 0.178 & 0.162 & 0.184 & 0.102 \\
\hline CLO & & & & 1.00 & 0.361 & 0.479 & 0.291 & 0.212 \\
\hline $\mathrm{HOU}$ & & & & & 1.00 & 0.159 & 0.065 & 0.047 \\
\hline SHB & & & & & & 1.00 & 0.493 & 0.388 \\
\hline $\mathrm{COK}$ & & & & & & & 1.00 & 0.703 \\
\hline DRK & & & & & & & & 1.00 \\
\hline
\end{tabular}

Where; KTW: Knowledge of Treated Wastewater; AGR : Agriculture or Landscaping; AUT: Automobile wash; CLO : Cloth washing; HOU : House washing/scrubbing; SHB : Showering/Bathing; COK : Cooking; DRK : Drinking.

The variable most strongly correlated with the people's willingness to use treated wastewater was agriculture or landscaping $\left(\mathrm{r}_{\mathrm{xy}}=0.503, \mathrm{p}<0.0001\right)$. However, in addition to agriculture or landscaping, a number of other variables may also significantly affect the treated wastewater consumption, all of which conform to expectations:

- $\quad$ automobile/car washing $\left(\mathrm{r}_{\mathrm{xy}}=0.409, \mathrm{p}<0.0001\right)$

- $\quad$ house washing/scrubbing $\left(\mathrm{r}_{\mathrm{xy}}=0.176, \mathrm{p}<0.0001\right)$

- $\quad$ clothes washing $\left(\mathrm{r}_{\mathrm{xy}}=0.117, \mathrm{p}<0.0001\right)$

- $\quad$ human showering/bathing $\left(\mathrm{r}_{\mathrm{xy}}=0.097, \mathrm{p}<0.0001\right.$, cooking $\left(\mathrm{r}_{\mathrm{xy}}=0.0 .72, \mathrm{p}<0.0001\right)$

- $\quad$ drinking $\left(\mathrm{r}_{\mathrm{xy}}=0.037, \mathrm{p}<0.0007\right)$

\section{FORECASTING TREATED WASTEWATER EFFLUENT}

In this part of the research, we used time series methodology in forecasting treated wastewater outflow (effluent). This methodology has not been used before in forecasting outflows for public utilities in Kuwait.

In time series, the series is first examined for stationary. This can be done by computing the autocorrelation function (ACF) and the partial autocorrelation function (PACF) for the original series (Granger and Newbold, 1986; Newbold and Bos, 1994) or by formal unit root analysis (Dicky et al., 1986). The correlograms associated with ACF and PACF are often good visual diagnostic tools (Hanke and Reitsch, 1995). The tentative model is then estimated. A number of alternative parameter estimation procedures are commonly used. These various procedures typically yield quite similar estimates when the sample size is large. However, for shorter series, there can be larger differences, particularly if the model involves substantial moving average terms. The full-maximum likelihood approach is usually preferred in those cases for which different estimation procedures yield significantly different results (Newbold and Bos, 1994). The residuals from the tentative model are examined to determine whether or not they are white noise. The adequacy of the model is also indicated by the Box-Ljung statistic (Box and Jenkins, 1970; Ljung and Box, 1978). Model inadequacy is indicated by large absolute values for the residual autocorrelations and consequently large values for the Box-Jenkins statistic. If the residuals are white noise, the tentative model is 
probably a good approximation of the underlying stochastic process. If they are not, then the process is started all over again. Therefore, the Box-Jenkins modelling involves identifying an appropriate Autoregressive Integrated Moving Average (ARIMA) process, fitting it to the data, and then using the fitted model for forecasting. One of the attractive features of the Box-Jenkins approach to forecasting is that ARIMA processes are a very rich class of possible models and it is usually impossible to find a process which provides an adequate description to the data (Box and Jenkins, 1970).

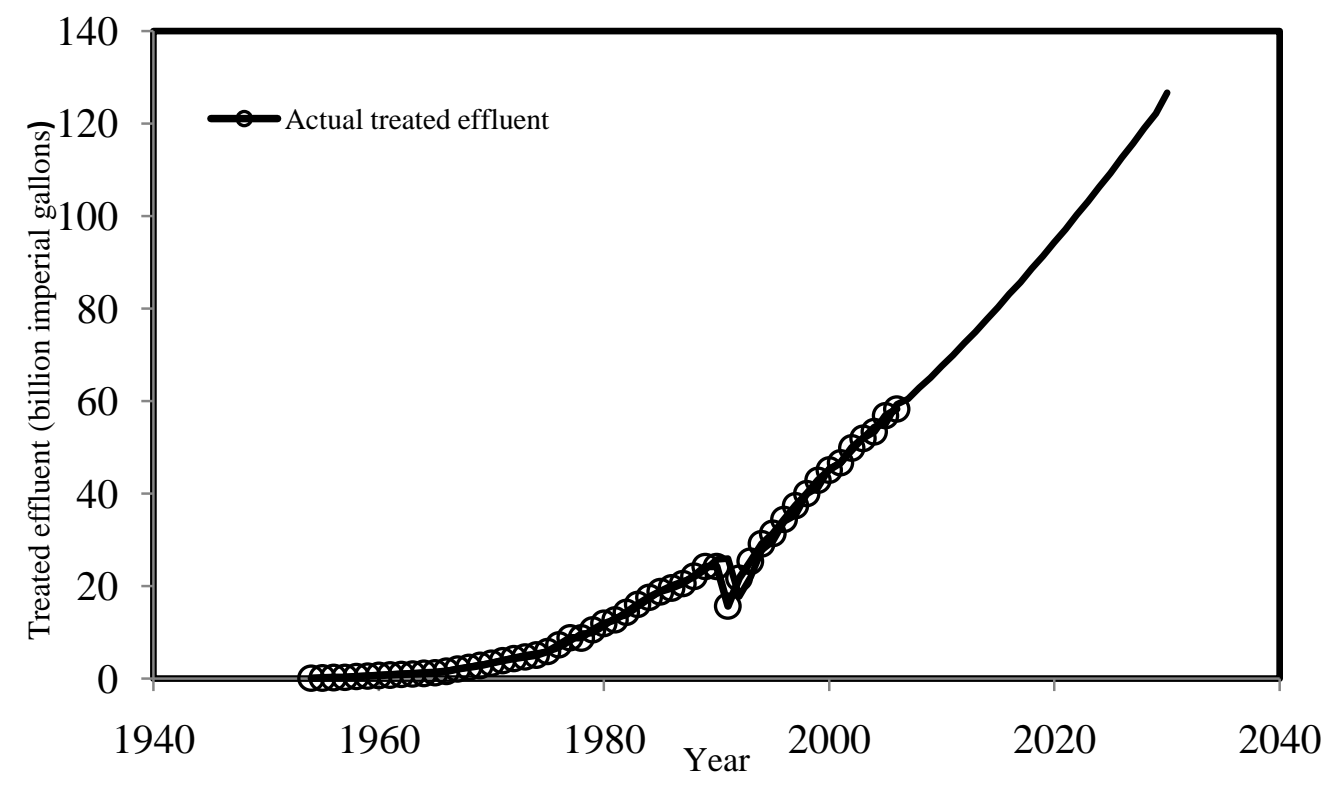

Figure 8: Actual and Predicted Treated Wastewater Effluent

Table 7: Statistical Analysis Results

\begin{tabular}{cccccc}
\hline \multicolumn{1}{c}{ Parameter } & Estimate & Std. Error & t-value & Approx. Pr $>|t|$ & Lag \\
\hline MU $^{1}$ & 96.87334 & 364.864 & 0.27 & 0.7906 & 0.9054 \\
MA1 & 0.01748 & 0.14713 & 0.12 & & \\
Constant Estimate & 96.87334 & & & & \\
Variance Estimate & 6831202 & & & \\
Std. Error Estimate & 2613.657 & & & \\
AIC & 930.707 & & & \\
SBC $^{4}$ & 934.531 & & &
\end{tabular}

\begin{tabular}{cccccccccc} 
To Lag & $\begin{array}{c}\text { Chi- } \\
\text { square }\end{array}$ & DF & Pr $>$ Chi- & \multicolumn{3}{c}{ Autocorrelations } \\
6 & 19.81 & 6 & 0.0001 & -0.010 & -0.581 & -0.035 & 0.135 & 0.079 & -0.039 \\
12 & 23.90 & 12 & 0.0001 & -0.055 & -0.094 & -0.048 & 0.147 & -0.163 & -0.020 \\
18 & 27.73 & 18 & 0.0002 & 0.187 & -0.080 & 0.087 & 0.034 & 0.055 & 0.010 \\
24 & 27.93 & 24 & 0.0001 & -0.017 & -0.011 & 0.016 & 0.016 & 0.012 & -0.033 \\
\hline
\end{tabular}

1 parameter estimate

2 moving average process

${ }^{3}$ Akaike's Information Criterion

${ }^{4}$ Schwartz's Bayesian Criterion 
The model finally selected can then be used for forecasting. Forecasts can be made for a single period or for several periods in the future. Confidence intervals can also be constructed about these estimates. In general, the further into the forecast, the larger the confidence intervals will be. Therefore, as more data become available, the same model can be used to revise the forecasts by choosing a different time origin (Box and Jenkins, 1970; Hoff, 1983; Chatfield, 1989; Anderson, 1994; Hamilton, 1994; Anderson and Finn, 1996; Fuller, 1996; Anderson, 2003).

As in our case, a series of 53 observations, representing total annual residential water consumption in Kuwait during the period 1954 to 2006, was collected. As seen before, Figure 8 gives a plot of the original series. A close inspection of the figure suggests that water consumption in Kuwait experienced exponential growth over the sample period with the exception of the period 1990-1992. The reason for this was explained earlier in the paper.

The series suggests a constant proportional growth rate of approximately 8 percent per annum. This was estimated using the regression:

$\operatorname{Ln} C_{t}=b_{o}+b_{1} T+u_{t}$

Where $\mathrm{C}_{\mathrm{t}}$ is the total annual water consumption in period $t, \mathrm{~T}$ is time, $\mathrm{b}_{0}$ and $\mathrm{b}_{1}$ are constants and $\mathrm{u}_{\mathrm{t}}$ is the error term. The coefficient $b_{1}$ represents the (constant) proportional rate of growth (r), given by:

$\mathrm{r}=(\mathrm{dC} / \mathrm{dT}) / \mathrm{C}$ follows:

The final model was estimated using SAS program (SAS/ETS Software, 1991) and it can be written as

$\mathrm{Y}_{\mathrm{t}}+96.6=0.11\left(\mathrm{Y}_{\mathrm{t}-1}+96.6\right)+\mathrm{e}_{\mathrm{t}}$

Where $Y_{t}$ is the series of water consumption and $e_{t}$ is the error term. As shown in Figure 8 and Table 7, the above model appears to provide a good fit for the water consumption. None of the $\mathrm{Q}$ statistic values are significant and none of the residual autocorrelations are very large in the autocorrelation check of residuals, indicating that the model provides a good fit to the data. The seasonal moving average parameter estimate of 0.11 is significant. In addition, the Akaike's Information Criterion (AIC) (Akaike 1974, Harvey 1981) and Schwartz's Bayesian Criterion (SBC) (Schwartz 1978), which measure the goodness of fit, are small, indicating good fit of the model. Moreover, more elaborate models did not produce superior results. Therefore, this model adequately describes the behavior of the water consumption time series. Figure 8 shows how close the forecasted values (2007-2030) given by the model to the actual values are, and the results suggest a very good fit.

\section{CONCLUSION AND RECOMMENDATIONS}

This study has provided detailed information regarding reusing treated wastewater in Kuwait, which was further enhanced as a result of the construction and operation of Sulaibiya wastewater treatment plant. The paper indicates the importance of consulting with the community regarding water reusing options.

This study adds to existing international literature regarding wastewater treatment plants for recycled water and indicates a significantly higher figure than previously found. Research with other countries would be beneficial to further clarify how variable wastewater treatment plants for recycled water is between locations and to foster a greater understanding of under what circumstances wastewater treatment plants would change, especially in relation to water scarcity.

\subsection{Conclusion}

Kuwait is a small country with very scarce land resources. Therefore, wasting advanced treated wastewater is unsound and impractical, both economically and environmentally. Reclaimed water is an important water resource. Its use in agriculture is becoming established as an alternative to treatment for disposal to water courses. Reclaimed wastewater is the only source of additional water for irrigation, industry and urban non-potable reuse that actually increases in quantity as the population and water consumption grow.

Advanced treated effluents are produced in Kuwait and they could be discharged into artificially constructed wet lands. This could reduce the need for storage, create much needed wetlands for their aesthetic and recreational value, as well as provide a sanctuary for migratory birds wintering annually in the area.

A good starting point for future reuse of effluents for industry could be in areas close to wastewater treatment plants. With regard to potable use in Kuwait, the cost of producing advanced effluents is low compared to 
fresh water. It costs about US\$ 0.784 to produce 1,000 liters of reclaimed water. This compares with US\$ 3.138 per 1,000 liters for desalinated water. The difference between the two figures is more than fourfold.

It is apparent that people in Kuwait are bothered most about reusing advanced treated wastewater for drinking, cooking, showering/bathing and clothes washing. Public awareness and education programs, perhaps the most important and necessary factor for an efficient wastewater management system in the State of Kuwait, conducted by both the government and public/private interest groups can help promote reuse significantly. Information flyers, booklets, and "home water/wastewater guides" can provide the consuming households/industries with extensive lists of reusing suggestions. The educational programs should strongly emphasize the negative health and environmental impacts of high waste generation and poor waste management.

Moreover, using advanced treated wastewater could yield many advantages to Kuwait; namely:

- $\quad$ satisfy the ever-increasing demand for good quality water for irrigation, industrial and certain demand usage

- $\quad$ preserve the natural strategic water resources (brackish water)

- $\quad$ meet unexpected emergency situations of shortages in fresh water production from the sea for certain domestic applications

- $\quad$ save funds needed to construct new desalination plants because the demand for fresh water will be reduced and stabilized with the utilization of treated effluent for irrigation and other applications

\subsection{Recommendations}

The following recommendations are worthy of further detailed consideration:

- $\quad$ Periodic training should be undertaken of wastewater treatment plant and authorities' personnel responsible for wastewater effluents.

- The development of good public relations offices in the Ministry of Electricity and Water and Ministry of Public health would have many advantages. Such offices would carry the tasks of awareness and education of the public regarding relevant uses of treated wastewater.

- $\quad$ Political leaders in the Kuwaiti parliament should be advocating wastewater reuse. Usually those leaders have political power; in addition, some people view them as ideals. Therefore, they could influence people to accept using treated wastewater through different means, such as public campaigning, seminars, meetings, etc.

Therefore, the responsible authorities should start an awareness campaign to inform the public about the reuse of treated wastewater in different fields. Public awareness programs should be introduced to educate and inform the public about reclaimed water and its suitability for various uses. For example, from the point of view of the Islamic religion, the concept of wastewater effluent reuse was given a great impetus by a legal ruling from the religious scholars of the Ministry of Awqaf and Islamic Affairs of Kuwait. The ruling declared that treated wastewater can be used for all religious rituals and was considered clean for human use (drinking, washing, etc.) if it meets the health standards (Alrai, 2007). If this ruling was given a wider public airing, it could have had a substantial impact on public attitudes.

Kuwait has invested heavily in constructing two independent distribution facilities, one for fresh water and the other for brackish water. The capacity of the brackish water network is over 160 million imperial gallons per day (772 thousand $\mathrm{m}^{3} / \mathrm{day}$ ), yet it is currently very much underutilized. In other words, the great investment in the brackish water distribution system is losing its value with time, without optimum utilization of the system. However, the produced water from the Sulaibiya plant is distillate in quality and free from viruses, bacteria, pathogens, sewage organic and toxic materials. Therefore, it can be safely blended with brackish water and distributed through the existing brackish water distribution facilities for various beneficial uses or safely injected in the underground aquifers.

In recent years, the Build-Operate-Transfer (BOT) approach has placed a growing role in the implementation of industries and infrastructure projects, such as oil and gas fields, power plants, toll roads and water supply and treatment facilities, in both industrialized and developing countries. Kuwait should highly encourage such an approach because the private sector strives on profits; therefore, with good observations and management from the government side, private companies can build and construct big and expensive projects in a very short period of time. For example, since the 1980's, MPW has had a plan to build a new town in the Subeya area (AlHarrer City) that should be able to accommodate 500,000 people, but the project has not yet seen the light. 


\subsection{Future Research}

Construction of advanced wastewater treatment plants is very costly, but at the same time, very useful in many ways. Therefore, future research could concentrate on the following:

- $\quad$ Comparison of the perception of users within different countries. The study should measure the influence of culture, religious believes, etc.

- Qualitative research with experts regarding the way the project is managed (communication, education program, training sessions for workers, etc.)

\section{ACKNOLEDGMENTS}

The authors are thankful to the Ministry of Public Works and to Utilities Development Company for providing us with the information and data of the plant. In addition, the authors are grateful to the distinguished reviewers of the journal for their insightful comments and suggestions.

\section{AUTHOR INFORMATION}

Dr. Jasem M. Alhumoud is an associate professor, professional engineer and consultant environmental/civil engineer. Currently working at Kuwait University in the Civil Engineering Department. He has a Ph.D. from the University of Pittsburgh, USA, in Civil and Environmental Engineering. His research and scholarly activities have been devoted to solid waste management, wastewater utilization/reuse and management, hydrology and hydraulics, geoenvironmental, geo-hydrology engineering, water resources engineering. In addition, he has done some work in coastal management. He has published more than 40 papers on those topics. Dr. J. Alhumoud can be contacted at the Civil Engineering Department, Kuwait University, P.O. Box 5969, Safat 13060, Kuwait, email: Jasem@ kuniv.edu.kw.

David Madzikanda is an associate professor he has a Ph.D. in business administration with specialty in strategic management. Currently he is working at Masstricht School of Business in Kuwait. Dr. Madzikanda can be contacted at Kuwait-Maastricht Business School, Block 3, Kazima Street, Dasma, Kuwait, e-mail: David@kmbs.edu.kw.

\section{REFERENCES}

1. Akaike, H.. A new look at statistical model identification. IEEE Transaction on Automatic Control, AC-19, 716-723, 1974.

2. Alhajri, F., Forecasting water consumption in Kuwait, Master Thesis, Kuwait University, Civil Engineering Department, Kuwait, 2005.

3. Alhumoud, J.M., Fresh Water Consumption in Kuwait: Analysis and Forecasting, Journal of water supply: Research and technology-AQUA, Vol. 57, No. 4, pp. 279-288, 2009.

4. Al-Rai, A.A.. 'The ministry of Awqaf and Islamic Affairs declared that treated wastewater can be used for all religious rituals', Issue No. A0-10401, Kuwait, 2007.

5. Al-Ruwaih, F., Shehata, M. and Al-Awadi, E., Groundwater Utilization and Management in the State of Kuwait, Water international, Vol.25, No. 2, pp. 378-389, 2000.

6. Al-Sofi, M.A.,Water scarcity-The challenge of the future. Desalination, Vol. 98, pp. 425-435, 1994.

7. Al-Zubari W. K., Towards the Establishment of a Total Water Cycle Management and Re-use Program in the GCC Countries, Desalination, Vol. 120, pp. 3-14, 1998.

8. Anderson, T. W.. The statistical analysis of time series. John Wiley \& Sons, INC, 1994.

9. Anderson, T. W. An introduction to multivariate statistical analysis. $3^{\mathrm{rd}}$ edition, John Wiley \& Sons, INC, 2003.

10. Anderson, T. W. and Finn, J. D. The new statistical analysis of data. Springer-verlag, N.Y., 1996.

11. Asano T, Maeda M and Takaki M., Wastewater Reclamation and Reuse in Japan: Overview and Implementation Examples, Water Science and Technology, Vol. 34, No. 11,pp. 219-226, 1996.

12. Baumann, D.D., Social acceptance of water reuse. Applied Geography, Vol. 3, pp. 79-84, 1983.

13. Bruvold, W.H., Ward, P.C., Public Attitudes Toward Uses of Reclaimed Wastewater, Water \& Sewage Works, pp. 120-122, 1970.

14. Bruvold, W.H., Olson, B.H., Rigby, M., Public Policy for the Use of Reclaimed Water, Environmental Management, Vol. 5, pp. 95-107, 1981.

15. Bruvold, W.H., Public Opinion on Water Reuse Options, Journal WPCF, Vol. 60, pp. 45-49, 1988.

16. Busheri, M. and Burney, N., Evaluation of the Impact of Subsidy Reform Policies in the State of Kuwait, Informal report, Kuwait Institute for Scientific Research, Kuwait, 2003.

17. Comrie, D., Evans, S., Gale, R., Kitney, P., Taste and Odour in Drinking Water: A Perception Versus Reality Case Study, International Water, Perth, WA, 2003. 
18. Dolnièara, S. and Saunders, C., Recycled Water for Consumer Markets - a Marketing Research Review and Agenda. Desalination, Vol. 187, pp. 203-214, 2006.

19. Dolnicar, S. and Schafer, A. I. , Desalinated Versus Recycled Water: Public Perceptions and Profiles of the Accepters. Journal of Environmental Management, Vol. 90, pp. 888-900, 2009.

20. Fuller, W. A. Introduction to time series, $2^{\text {nd }}$ edition, John Wiley \& Sons, INC, 1996.

21. Gottberg V., Gange A. D., Vaccaro G. and Elyanow D., World's Largest Membrane-Based Water Reuse Project, Proceedings of the AWWA Membrane Technology Conference, Atlanta, GA, USA, 2003.

22. Gottberg V. and Vaccaro G., Kuwait's Giant Membrane Plant Starts to Take Shape, The international desalination and water reuse, Vol. 13, No. 2, 2003.

23. Hamilton, J. D. Time series analysis. Princeton University Press, Princeton, N.J., 1994

24. Hankee, J. E. and Reitch, A.G. Business forecasting, $5^{\text {th }}$ edition, Englewood Cliffs, New Jersey, Prentice Hall International Inc., 1995.

25. Harvey, A.C. The economic Analysis of time series, New York: John Wiley \& Sons, INC., 1981.

26. Higgins, J., Warnken, J., Sherman, P.P., Teasdale, P.R., Surveys if Users and Providers of Recycled Water: Quality Concerns and Directions for Applied Research, Water Research, Vol. 36, pp. 5045-5056, 2002.

27. Hoff, J. C. A practical guide to Box-Jenkins forecasting, Belmont, CA. Lifetime Learning Publications, 1983.

28. Hurlimann, A.C., Water Supply in Regional Victoria Australia: A Review of the Water Cartage Industry and Willingness to Pay for Recycled Water, Resources, Conservation and Recycling, Vol. 53, pp. 262-268, 2009.

29. Hurlimann, A.C. and McKay, J.M., What Attributes of Recycled Water Make it fit for Residential Purposes? The Mawson Lakes experience, Desalination, Vol. 187, pp. 167-177, 2006.

30. Hurlimann A. and McKay J.M., Urban Australians Using Recycled Water for Domestic Non-Potable Use-An Evaluation of the Attributes Price, Saltiness, Colour and Odour Using Conjoint Analysis, Journal of Environmental Management, Vol. 83, pp. 93-104, 2007.

31. Kasperson, R.E., Baumann, B., Dwarkin, D., McCauley, D., Reynolds, J., Sims, J., Community Adoption Water Reuse System in the United States, US Department of the Interior, Office of Water Resources Research, Washington, DC, 1974.

32. KEPS, Kuwait Environment Protection Society, Water ...Crises. Vol. 228, Kuwait, 2004.

33. Kotchen, M., Kallaos, J., Wheeler, K., Wong, C., and Zahller, M., Pharmaceuticals in Wastewater: Behavior, Preferences, and Willingness to Pay for a Disposal Program, Journal of Environmental Management, Vol. 90, pp. 1476-1482, 2009.

34. Ljung, G. M. and Box, G. E. P. On a measured of lack of fit in time series models. Biometrica, Vol. 165, 279303, 1978.

35. Marks, J.S., Taking the Public Seriously: the Case of Potable and Non Potable Reuse, Desalination, Vol. 187, pp. 137-147, 2006.

36. Mecalf and Eddy, Wastewater Engineering; Treatment and Reuse, $4^{\text {th }}$ edition, McGraw Hill, New York, USA, 2003.

37. Menegakia, A., N., Hanleya, N., and Tsagarakis, K. P., The social Acceptability and Valuation of Recycled Water in Crete: A study of Consumers' and Farmers' Attitudes, Ecological Economics, Vol. 62, pp. 7-18, 2007. Milliken, J.G., Lohman, L.C., Analysis of Baseline Survey: Public Attitudes About Denver Water and Wastewater Reuse, Journal of American Waterworks Association, Vol. 77, No. 72, 1985.

39. MEW, Ministry of Electricity and Water. Statistical Year Book (Water). Edition 32 “B”. Kuwait, 2007.

40. MOP, Ministry of Planning, Annual Statistical Abstract. Edition 36. Kuwait., 2004.

41. Newbold, P. and Bos, T. Introductory business and economic forecasting. Cincinnati, Ohio. South-Western Publishing Co., 1994.

42. Olson, B.H., Henning, J.A., Marshack, R.A., Rigby, M.G., Educational and Social Factors Affecting Public Acceptance of Reclaimed Water, Water Reuse Symposium, Denver, CO, pp. 1219-1231, 1979.

43. Po, M., Kaercher, J.D., Nancarrow, B.E., Literature Review of Factors Influencing Public Perceptions of Water Reuse, Technical Report No. 54/03, CSIRO Land and Water, 2004.

44. Russell, S., Community Responses and Consultation, University of Wollongong, Wollongong, Australia, 2004.

45. SAS/ETS Software: Applications Guide 1, Time Series Modeling and Forecasting, Financial Reporting, and Loan Analysis, Version 6, $1^{\text {st }}$ edition, Cary, N.C. USA, 1991.

46. Sims, J.H., Baumann, D., Renovated Waste Water: The Question of Public Acceptance. Water Resources Research, Vol. 10, pp 659-665, 1974.

47. Stone, R., Kahle, R., Wastewater Reclamation. In: Socio Economics, Technology and Public Acceptance, Office of Water Resource Research, US Department of the Interior, Washington, DC, 1974.

48. Walpole, R.E. and Myers, R.J., Probability and Statistics for Engineers and Scientists, $3^{\text {rd }}$ edition, Macmillan Publishing, New York, USA, 1985.

49. World Bank, A Water Sector Assessment Report on the Countries of the Cooperation Council of the Arab States of the Gulf, Report No. 32539-MNA, 2005.

50. Vazquzio O., Horan N J and Mara D. D., Management of Domestic Wastewater for Reuse in Irrigation, Water Science and Technology, Vol. 33, No. 10-11, pp. 355-362, 1996. 